\title{
Problem Solving and IMC (International Mathematics Competition) Activities in Göttingen
}

Chenchang Zhu (Universität Göttingen, Germany)

This article is about some interesting mathematics activities I do with some of my students and some of my colleagues in Göttingen - once the home of Gauss, Riemann, Hilbert, Noether and other beloved and respected mathematicians.

Since 2011, Dima Dudko and I open a course or seminar on mathematics problem solving every Summer semester for university students. At the beginning of the course, we give lectures on various problems in analysis, number theory, algebra and geometry. We propose problems and ask the students to solve them during the lecture. Then we give hints and summarise the cool points of the problems. The students may also propose their own solutions. Later, it becomes a show for the students themselves. They are in charge of looking for problems and presenting them, and asking their fellow students to solve them during the seminar. We usually gather 10-20 people each year, which makes it manageable. We especially want to emphasise the beauty and fun in mathematics, to challenge the rejecting and fearful feelings most of our students have at the beginning of university. We also try to establish a collaborative environment instead of competitive one, and promote discussion and sharing.

After two classes, we conduct two exams in the seminar, each consisting of six problems in four hours. This is a selection exam. The best three or four students will represent Göttingen in attending the International Mathematics Competition for University Students (IMC) ${ }^{1}$ held in Blagoevgrad, Bulgaria. Our faculty and university (Unibond) give us funding to cover travel and registration for the IMC.

Although these three or four students are selected, everyone still attends the seminar and presentations go on. For these three or four students, we offer more exams to prepare them for the IMC test. After years of effort, we have gradually achieved good results in the IMC and are able to attract new maths talents to join our maths institute in Göttingen. This is also connected to MO in Niedersachsen, which is organised by my students for high school and elementary schoolchildren. More will appear on this event in a later article.

The IMC is a competition now held every year during the last week of July or the first week of August. There are now 300-400 participants from across the entire world, from around 60-70 countries. In 2016, the team of Göttingen ranked sixth in the world. In 2018, we

1 The website of IMC is http://imc-math.org.uk/. even received a Grand First Prize (almost perfect score) for Christian Bernert. This is granted to only two students amongst the 351 students from all over the world. Recalling his experience, Christian said: "There was one moment during the closing ceremony of this year's IMC where I finally didn't know the answer. It was the granting of the Grand First Prizes and the two winners, Daniel Klyuev from St. Petersburg and me, were on stage in front of the other 350 students. For Daniel, this was already the third time winning this prize but for me, it was a completely new and utterly unexpected experience. I had competed at the competition already for the third time, with some success in the previous years. But I would have never expected to perform that well.

It was at this moment where John Jayne, the longstanding organiser of this great event, told the students in the crowd to ask us, the winners, for our secret at the final dinner. Fortunately, no one actually followed this advice, for the only thing I would have been able to tell them is to continue to do math, to have fun doing it, to feel no pressure and to hope for quite a bit of luck."

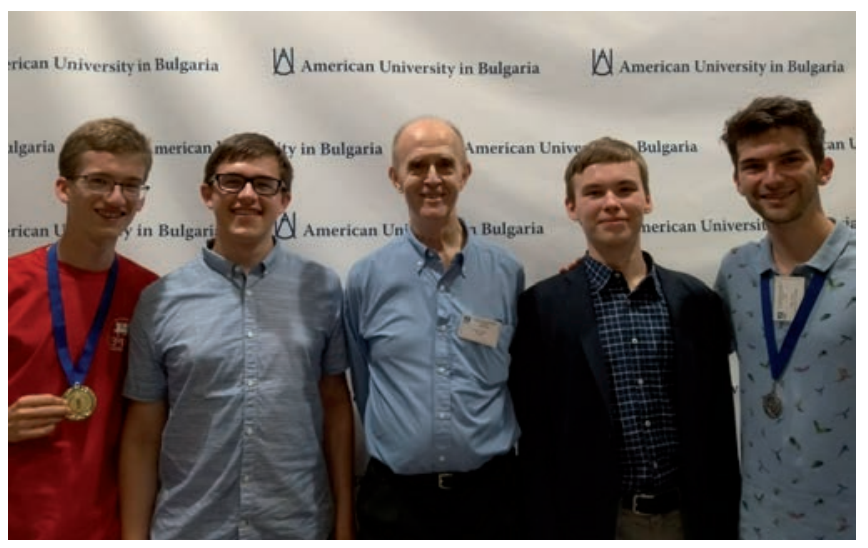

Team photo with John Jayne.

As a female mathematician, and since Göttingen is the home university of the famous female mathematician Emmy Noether, I also try to encourage female students to join us in mathematics, or at least to overcome their fear of mathematics. We have always had several female students in our seminar of problem solving. I have to admit that we have not yet had any girls on our IMC team. For this, we also do something especially for high school girls, to promote their interest in mathematics, in the spirit of starting early. In our view, encouraging girls at an early stage to do mathematics is vital in order to compensate for classical stereotypes, which are unfortu- 


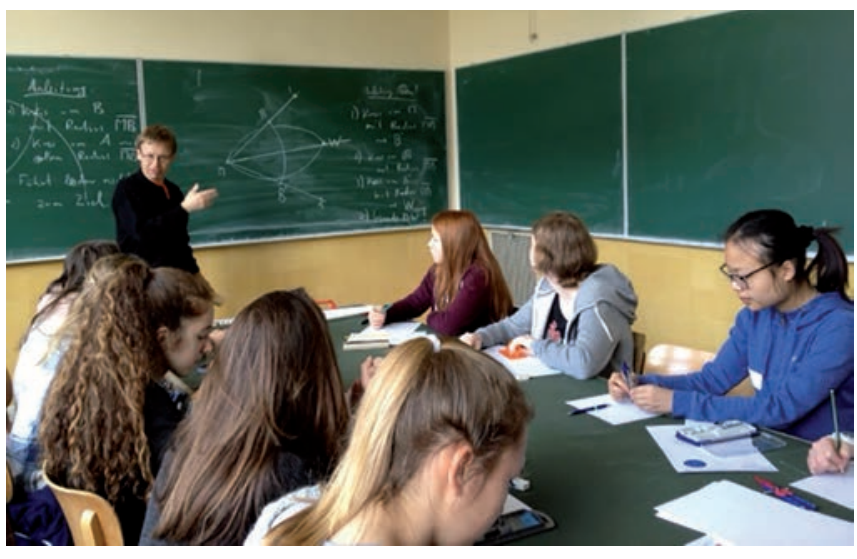

Girls day.

nately still present in society and can be quantitatively assessed in self-assessment studies of high school children. That is why, within the framework of the German "Zukunftstag" (future-day) and "girls-day", together with my colleagues Anna-Lena Martins and Robin Richter in the equal opportunity office, we organise a day that should give girls aged from 10 to 15 a peek into the study of mathematics. The day has two main targets that we try to achieve via group exercises and riddles, library and mathematical exhibition exploration, a little introduction to logic and the sharing of experiences by faculty members and students. First of all, we want to show that there exists a very rich world outside of "high school

2 There is also a "boys-day" event, and some event which can be included in both frameworks. mathematics" that is worth exploring. Logical exercises and riddles are especially well suited for this, since they are completely different from German "school mathematics" whilst being challenging and intuitive at the same time. Secondly, we want to emphasise the teamworking character of mathematics. From the first years in Göttingen, exercise sheets have often been solved in interacting groups of students who organise themselves, an aspect that differs greatly from their experience of school and often from the expectations with which new students come to university. During the day, female $(\mathrm{PhD})$ students and professors engage to give insight into their routes through life, thus establishing important role models that the girls might want to follow. We hope events like this will encourage girls to participate in mathematics at university and avoid lost talent because of traditional gender bias.

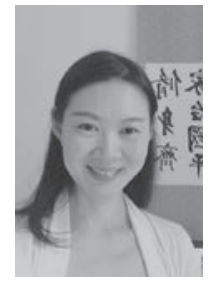

Chenchang Zhu has been tenured at the University of Gottingen since 2013 and, before moving to Gottingen in 2008, she was Maitre de conferences (assistant professor) at the Fourier Institute, Grenoble (from 2006), a post-doc at ETH Zurich (20042006) with Giovanni Felder, a PhD student at U.C. Berkeley with advisor Alan Weinstein (until 2004) and an undergraduate at Bei Jing University. Since 2011, she has been in charge of the selection of the IMC team and training in Göttingen. 